\title{
Implementation and Follow-Up of Medical Abortion in Catalonia (2010-2014)
}

\author{
Carme Ollé1, Roser Bosser2*, Rosa Gispert², Neus Prat'3, Pilar Magrinyà ${ }^{4}$, Carme Coll5, \\ Ramón Escuriet ${ }^{1}$, Ricard Tresserras ${ }^{4}$, Joaquim Calaf ${ }^{6}$
}

${ }^{1}$ Subdirectorate-General for the Service Porfofolio and Health Map, Directorate-General for Health Planning, Ministry of Health, Barcelona, Spain

${ }^{2}$ Studies Service, Directorate-General for Health Planning, Ministry of Health, Barcelona, Spain

${ }^{3}$ Sexual and Reproductive Health Services, Directorate-General for Health Planning (ASSIR), Costa Ponent, Barcelona, Spain

${ }^{4}$ Directorate-General for Health Planning, Ministry of Health, Barcelona, Spain

${ }^{5}$ Sexual and Reproductive Health Services, Directorate-General for Health Planning (ASSIR), Barcelonès Nord i Maresme,

Barcelona, Spain

${ }^{6}$ Chair of Obstetrics and Gynaecology, Autonomous University of Barcelona, Barcelona, Spain

Email: *roser.bosser@gencat.cat

How to cite this paper: Ollé, C., Bosser, R., Gispert, R., Prat, N., Magrinyà, P., Coll, C., Escuriet, R., Tresserras, R. and Calaf, J. (2017) Implementation and Follow-Up of Medical Abortion in Catalonia (2010-2014). Open Journal of Obstetrics and Gynecology, 7, 208-219.

https://doi.org/10.4236/ojog.2017.72022

Received: November 15, 2016

Accepted: February 18, 2017

Published: February 21, 2017

Copyright ( 92017 by authors and Scientific Research Publishing Inc. This work is licensed under the Creative Commons Attribution International License (CC BY 4.0).

http://creativecommons.org/licenses/by/4.0/

(c) (i) Open Access

\begin{abstract}
In 2011 a protocol for medical abortions (MA) up to 49 days of pregnancy was approved by the Ministry of Health of Catalonia's autonomous government and it was progressively introduced through the public network of the Sexual and Reproductive Health Units (SRHU). In 2014, a new protocol extended to 63 days of pregnancy was set up. Data come from the official abortion registry held by the Ministry of Health, which collects statistical data from all abortions performed in Catalonia. Since 2011, the number and rate of abortions in Catalonia have decreased while the number of health centers providing abortions has increased, especially the SRHU. The proportion of MA abortions went from $0.4 \%$ (2010) to $36.9 \%$ (2014), while the percentage of early abortions (up to 7 weeks) surged by $14.7 \%$. SRHU reported $73.4 \%$ of all MA and hospitals performed $18.7 \%$ of the total, while outpatient centers accounted for the remaining 7.9\%. Compared to surgical abortions, women having had MA have higher levels of education and lower rates of unemployment. Furthermore, they have more living offspring and fewer previous terminations as well as more frequent attendance to a public family planning center.
\end{abstract}

\section{Keywords}

Medical Abortion, Catalonia, Early Abortions, Sexual and Reproductive Health Units (SRHU) 


\section{Introduction}

Medical abortion (MA), a non-surgical intervention which involves the use of medication for the termination of pregnancy (TOP), has become a good alternative, since the availability of prostaglandins and antiprogestins [1]. Development of these medical termination strategies can overcome the problems of availability of services in some geographic areas and can enable women to have more control and choices [2]. MA offers some advantages but also has inconveniences being well accepted by those having experienced the intervention [3].

The documented risks of MA include heavy bleeding, infection and incomplete abortion and it implies longer period for completion and more visits than surgical abortion. Failure rate is higher than with surgical abortion. On the contrary, the most important benefits are that women don't require anesthesia, instruments or vacuum aspirator and the pregnancy could be ended earlier than with surgical abortion. Moreover, women could stay at home instead of going to a clinic. As MA induces miscarriage-like process, it appears to be more natural [4] [5].

On the other hand, surgical abortion anaesthetics and drugs to manage pain may cause side effects, in addition to the possible surgical complications, although these complications occur in less than one percent of cases. The benefits of surgical abortion are those of a quick option, predictable, over in a few minutes and highly successful. It's performed by a doctor with support of medical and counselling staff on site. Surgical abortion involves less medication than medical abortion [4] [5].

Since 1988, when mifespristone was licensed in France for medical abortion and in 2000 in which FDA approved a regimen in the United States [2], several countries have implemented early abortion programs. Nowadays, MA is being offered in abortion clinics with a wide range of coverage from the lower $21 \%$ of the total terminations in Germany in 2014, to the highest 94\% in Finland, for 2013 [1]. Therefore, the experience of European countries can shed light on this issue because MA is approved in most of Europe, and countries like France, Great Britain and Sweden, have had more than a decade of experience with its use [6].

In most European countries abortion is allowed during the first trimester, although after that period is permitted only under certain circumstances [7]. In Spain, legal abortion was introduced in 1985, in a law that decriminalized the abortion under the following three grounds [8]: in case of vital risk for women or to preserve physical as well as mental health (without any restriction of time), in case of rape (up to the week 12) and for severe fetal anomalies (until the 22th week of gestation). In 2010, a new law was launched in which the access to abortion “on women's request" was included up to the week 14, besides the provision of information on sexual and contraceptive programs as well as on the government policies to support the families [9].

This law [9] also introduced the financing of all abortions through the public budget, under any ground. This contrasted to the previous situation, which be- 
nefited only abortions due to medical indications. This modification was an important stimulus for the implementation of a program, and this allowed women to accede to early medical abortion. In Catalonia, a northeast Spanish region that has responsibility on planning and managing its own health system, the program was established in 2011.

The Word Health Organization (WHO) acknowledges that the availability of safe and effective medical methods (such as mifespristone and misoprostol) and its correct use is a great opportunity for women and for health professionals. Especially it is important for those who plan and manage sexual and reproductive health programs, since these treatments are included on the public health services provision. WHO states that the principles to improve the access and quality of care for abortion must include: being implemented from the countries' own health system, to be a process inclusive of multiple perspectives, to be participatory, to be equitable and without discrimination and finally to be based on the objectives of health and human rights [10].

All these principles are fulfilled by the project, the results of which are being presented in this paper. This project has been developed and implemented entirely in Catalonia with the aim of improving the quality and accessibility of care for abortion. The program development has been described on detail elsewhere [11] and implied different actions. First, a report about the efficacy, security and economic evaluation of the regimen of treatment proposed from the Agency for Health Information, Assessment and Quality (AIAQS) [12]. Secondly, the protocol development about the proposed doses [4] [13], because this regimen did not fit exactly with those authorized by Spanish Agency for Medicines and Health Products. In the third place, this treatment was included among the list of services with public financing. Moreover, the regulation allowed primary care units for sexual and reproductive health (SRHU) to deliver these treatments, also, the establishment of a procedure of derivation among providers, and finally a pilot test in five SRHU to check the feasibility of this new model of TOP therapy [14]. SRHU are community based health settings were sexual and reproductive health care is provided by gynecologists and midwifes. Thus, MA is provided in SRHU, in outpatients centers (private centers with public budgeting for some amount of activity), and in hospitals.

The aim of this paper is to describe the results of the program after its implementation and to show the demographic and reproductive profile of women that are seeking termination of pregnancy and using this medical alternative compared to the others.

\section{Methods}

\subsection{Procedure}

The regimen of medical abortion is based in oral mifespristone ( $200 \mathrm{mgr}$ ) administered at the clinic followed 24 - 48 hours later by oral misoprostol (for buccal absorption, $800 \mathrm{mgs}$ ) self-administered at home. This therapy model was intended and authorized first for its use up to 49 days of gestation [4], but in 2014, 
the protocol was updated and enlarged up to 63 days of gestation [13].

A woman requesting a TOP should always be attended in the first visit at the SRHU. There, she receives information about the alternatives to the TOP in a sealed envelope and advice about the procedure. This information must be clear, objective and understandable. It should includedifferent available options, technical procedures, risks and benefits, contraindications and the schedule for the process. Then, after a minimum period of 72 hours for reflection (as established by law), if she decides to finish her pregnancy, she returns to the SRHU, where mifespristone is administered in situ. She is informed about the possible side effects, symptoms of alarm, and she should sign the informed consent form. She is provided with the misoprostol and instructions for self administration at home that should be $24-48$ hours after the mifepristone intake. The last visit, after two weeks, is intended for control of the abortion and to provide contraceptive advice if necessary. Those who have medical indications (women's health problems or fetalanomalies) for the abortion are drift to the hospital of reference [4] [13].

\subsection{Data and Methods}

Data come from the official statistics of legal abortion for Catalonia held by the Ministry of Health of the autonomous government of Catalonia, to which reporting data is compulsory. It includes all voluntary interruptions of pregnancy performed in Catalonia, both in public and private health centers authorized, irrespective of the place of residence of the woman [15]. Data are collected with no personal identifiers, regarding the characteristics of the women who had a TOP, the clinical circumstances and procedures for the termination.

The analysis includes data for years 2010-2014. As the program was initiated progressively since 2011 (before, the only medical treatment available was the RU 486) the year 2010 is included in the analysis as a base line.

Percentage of medical abortion is calculated in relation to all the abortions performed by any method. Also the proportion of MA abortions up to $7^{\text {th }}$ week over all the abortions performed up to $7^{\text {th }}$ week. Abortion rate is calculated as all the abortions performed at any age among all women aged between 15 - 44 years old, both, residing in Catalonia.

To analyze the socio-demographic and reproductive profile of women, the most important variables are compared between women having had medical abortion and those under other methods for the year 2014. Demographic variables with a proportion of non-response higher than $5 \%$ are not presented.

\section{Results}

Since 2011 the number of health centers providing abortions has had an overall increase, from 34 to 73 . The number of outpatient centers has remained stable (12 centers), while hospitals have had an upward trend (from 22 in 2010 to 26 in 2014). Finally, SRHU skyrocketed from 0 to 34.

The total number and rate of abortion has been decreasing during the period analyzed. Proportion of medical abortions went from $0.4 \%$ (101) the year 2010 
before the start of the program (when RU 486 regimen, was the only medical treatment was available), to $36.9 \%(7,053)$ of the total abortions in 2014 . In addition, the proportion of early abortions (up to 7 weeks) rose from $52.6 \%(12,780)$ to $61.9 \%(11,841)$ (a $17.7 \%$ increase). In 2014 early abortions represented $81.7 \%$ $(4,232)$ of all the abortions carried out in SRHU (Table 1 ).

Introduction of MA as a method of TOP has had a sharp increase, mainly in the SRHU. In the hospitals it was used only in a few cases in 2010, representing the $0.0 \%$ (5) of the all terminations before the program and in $6.5 \%$ (1245) of all abortions performed in 2014. Main providers for MA in 2014 were the SRHU, with 73.4\% $(5,180)$ of all MA (7053). Moreover, hospitals performed 17.7\% (1245) of the total MA and outpatient centers $8.9 \%$ (628) (Table 2).

As it is depicted in Table 3, during the period of implementation of the program there has been an increase of the proportion of MA among all the methods used, reaching more than one third of the total abortions in 2014 (7053). In contrast, surgical options have decreased although are still accounting for more than $50 \%$ of the abortions performed in 2014 (61.7\%) (10,464).

Table 4 shows sociodemographic and reproductive variables of women who had MA in relation to those who had other methods for the year 2014. The profile of the women seeking MA is quite different from the others. The proportion

Table 1. Abortion trends. Catalonia, 2010-2014.

\begin{tabular}{|c|c|c|c|c|c|}
\hline & $2010^{*}$ & 2011 & 2012 & 2013 & 2014 \\
\hline Total abortions & 24,305 & 22,614 & 21,956 & 22,083 & 19,130 \\
\hline Abortion rate r $^{* *}$ & 14.8 & 14.0 & 13.7 & 14.1 & 12.5 \\
\hline MA (\%) & 0.4 & 5.6 & 21.1 & 28.9 & 36.9 \\
\hline Abortions up to 7 weeks (\%) & 52.6 & 54.0 & 60.8 & 60.9 & 61.9 \\
\hline MA failure (\%) & Not recorded & Not recorded & Not recorded & 2.0 & 2.1 \\
\hline
\end{tabular}

MA: Medical Abortion. ${ }^{\star} 2010$ is taken as a base line. MA, in this column, is referred to RU-468 in 2010 . ${ }^{* *}$ Rate per 1000 resident women $15-44$ years old. SRHU: sexual and reproductive health units.

Table 2. Abortion distribution according to procedure and center (\%). Catalonia $2010^{\star}-2014$.

\begin{tabular}{|c|c|c|c|c|c|c|c|c|c|c|c|}
\hline \multirow[b]{3}{*}{ Center } & \multirow[b]{3}{*}{ Procedure } & \multicolumn{10}{|c|}{ Year } \\
\hline & & \multicolumn{2}{|l|}{$2010^{*}$} & \multicolumn{2}{|l|}{2011} & \multicolumn{2}{|l|}{2012} & \multicolumn{2}{|l|}{2013} & \multicolumn{2}{|l|}{2014} \\
\hline & & Number & $\%$ & Number & $\%$ & Number & $\%$ & Number & $\%$ & Number & $\%$ \\
\hline \multirow[t]{2}{*}{ Hospitals } & MA & 5 & 0.0 & 44 & 0.2 & 424 & 1.9 & 1,155 & 5.2 & 1,245 & 6.5 \\
\hline & Other & 764 & 3.1 & 885 & 3.9 & 517 & 2.4 & 677 & 3.1 & 496 & 2.6 \\
\hline \multirow[t]{2}{*}{ Outpatient centres } & MA & 96 & 0.4 & 5 & 0.0 & 54 & 0.2 & 76 & 0.3 & 628 & 3.3 \\
\hline & Other & 23,440 & 96.4 & 20,463 & 90.5 & 16,801 & 76.5 & 15,021 & 68.0 & 11,581 & 60.5 \\
\hline \multirow[t]{2}{*}{ SRHU } & MA & 0 & 0.0 & 1,212 & 5.4 & 4,160 & 18.9 & 5,149 & 23.3 & 5,180 & 27.1 \\
\hline & Other & 0 & 0.0 & 5 & 0.0 & 0 & 0.0 & 5 & 0.0 & 0 & 0.0 \\
\hline TOTAL & & 24,305 & 100.0 & 22,614 & 100.0 & 21,956 & 100.0 & 22.083 & 100.0 & 19,130 & 100.0 \\
\hline
\end{tabular}

MA: Medical Abortion. ${ }^{\star} 2010$ is taken as a base line. MA, in this table, is referred to RU-468 in 2010 . Other: Other procedures. SRHU: Sexual and reproductive health units. 
Table 3. Abortion distribution according to the procedure (\%). Catalonia 2010-2014.

\begin{tabular}{cccccc}
\hline Procedure & 2010 & 2011 & 2012 & 2013 & 2014 \\
\hline MA & --- & 5.6 & 21.1 & 28.9 & 36.9 \\
Other medical & 1.0 & 1.2 & 0.8 & 1.3 & 0.9 \\
Surgical & 96.3 & 82.0 & 69.9 & 62.0 & 54.7 \\
Other & 2.7 & 11.3 & 8.2 & 7.8 & 7.4 \\
Total & 100.0 & 100.0 & 100.0 & 100.0 & 100.0 \\
\hline
\end{tabular}

Definitions: MA (Medical Abortion): Only the combination "Mifespristone + Misoprostol"; Other medical (Other medical procedures): Mifespristone (RU 486) or Misoprostol. Surgical (Surgical procedures): Dilatation + suction (or suction syringe in 2010). Other: Other surgical procedures: Dilatation + evacuation, Dilatation + uterine curettage, intrauterine injection, hysterotomy, hysterectomy. Other combinations: Other medical and surgical combinations and other methods not listed.

Table 4. Abortions: Women profile. Catalonia 2014.

\begin{tabular}{|c|c|c|c|c|}
\hline \multirow[t]{2}{*}{ Women Profile } & \multicolumn{2}{|c|}{$\begin{array}{c}\text { Total } \\
\text { abortions }\end{array}$} & \multicolumn{2}{|c|}{$\begin{array}{c}\text { Abortions } \leq 7 \text { weeks } \\
\text { pregnancy }\end{array}$} \\
\hline & MA & Other & MA & Other \\
\hline \multicolumn{5}{|l|}{ Sociodemographic } \\
\hline Mean age & 29.2 & 29.2 & 29.1 & 29.7 \\
\hline Age 25 - $39(\%)$ & 61.6 & 60.8 & 62.6 & 65.1 \\
\hline Living in couple (\%) & 53.3 & 42.4 & 51.6 & 40.9 \\
\hline Higher secondary education + university (\%) & 47.1 & 40.2 & 47.8 & 41.0 \\
\hline Unemployed (\%) & 16.5 & 19.6 & 16.3 & 15.9 \\
\hline Living in Catalonia (\%) & 99.4 & 92.2 & 99.5 & 96.9 \\
\hline Born in Spain (\%) & 59.7 & 53.2 & 59.3 & 56.9 \\
\hline \multicolumn{5}{|l|}{ Reproductive } \\
\hline Having children (\%) & 55.2 & 51.4 & 55.4 & 51.3 \\
\hline Previous termination (\%) & 34.0 & 36.1 & 34.9 & 39.7 \\
\hline Attendance to Family planning center (\%) & 83.3 & 63.6 & 85.2 & 65.4 \\
\hline \multicolumn{5}{|l|}{ Current termination } \\
\hline$\leq 7$ weeks pregnancy $(\%)$ & 84.0 & 49.0 & 100.0 & 100.0 \\
\hline In SRHU and Hospitals (\%) & 91.1 & 4.1 & 89.3 & 0.5 \\
\hline On woman's request (\%) & 95.3 & 84.4 & 99.7 & 99.4 \\
\hline Total abortions $(\mathrm{N})$ & 7,053 & 12,077 & & \\
\hline Abortions $\leq 7$ weeks pregnancy $(\mathrm{N})^{*}$ & & & 5923 & 5922 \\
\hline
\end{tabular}

MA: Medical Abortion (mifepristona + misoprostol). Other: Other procedures. ${ }^{\star}$ Abortions $\leq 7$ weeks pregnancy are included in the total abortions.

of women living in couple, being native of Spain and residents in Catalonia is higher. Furthermore the proportion of unemployed is lower and the education level is higher. They have more children, have a lower percentage of previous abortions and are attending more family planning clinics. In relation to the cur- 
rent abortion episode, one important difference among the two groups are the weeks of gestation, the ground, being higher the reason "at women's request" among the medical abortion users. When the analysis is restricted to the early abortions (up to 7 weeks) the differences between women in the two groups of optional methods, are similar to those observed for all abortions, except for age and reproductive background (older and having less children).

\section{Discussion}

This study presents the results of the implementation of the program for early medical abortion in Catalonia. Catalonia is the only region of Spain where the program was formally launched, although in some other regions of Spain some medical abortion therapies are also being used. Nevertheless MA method represented in 2013 at about the $11.3 \%$ of TOP performed in Spain, and $51.8 \%$ of those were performed in Catalonia [15] [16]. Although other therapies for medical abortion are being used in hospitals as adjuvant for surgical terminations, it does not represent a significant proportion.

According to our data, the program has shown very good results over these four years of implementation.

First, it has improved the accessibility to the TOP as it is shown by the increase of the number of SRHU offering that option and its distribution among the Catalan geography. Almost a third part of the total number of counties in Catalonia, have a SRHU. This important improvement has not implied an increase of the total number or rate of abortions. A steadily decreasing trend of the abortion rate has started in 2008 and it has been maintained up to now [15]. This is a very good result to be taken into account regarding the concerns expressed by some part of the medical and civil society when claiming that MA would make an abortion too easy and lead some women to take the decision lightly [17].

A second advantage, is that the proportion of early abortions increased, reducing the surgical abortion risks and those associated to anesthesia. Thus it has reduced the number of surgical procedures and it has modified the pattern of TOP procedures in the hospitals and as a consequence, it has reduced the costs. That is an important point, both for public as well as private finances, because MA has been estimated in the public settings to be nine times cheaper than surgical options [12] and because most of medical treatments are being made in public centers. In summary we may assert that this program has positive outcomes in both, in health and in economic terms.

Furthermore, the misoprostol intake at home reduces the number of visits and is well regarded for women [3] and the global rate of failures is similar to that described in the global literature [18].

Demographic profile of women who undergo MA is quite different from those that are seeking other methods. Women that had MA are more frequently living in couple, residing in the region and this group has less proportion of immigrants. This could be related to one of the disadvantages of the medical termina- 
tion that is a longer period for completion and a more number of visits to the clinics for safety reasons [17]. On the other hand, this group has higher economic level and higher educational background, what probably fits well with the feeling that MA enables the patients to have more control over their decision to abort [2]. The age distribution didn't show any difference between both groups.

These results are somewhat contradictory with other studies that show ethnicity, age, and status of residence not influencing the choice, but MA being more frequent in women haven't had previous children, pregnancies or terminations [19]. This is different from what we have found in Catalonia, where women who decided to have MA, have more children but no more previous terminations. Although it is difficult to speculate, the differences between these studies could be due to different cultural backgrounds, language barriers, or even unequal access to the programs.

The most important differences between the two main types of interruption (medical and surgical) are abortion grounds, which in the MA are almost entirely by women request. Also, and related to that, the gestational age, which is lower than in the other methods. When the ground for termination is a woman disease or a fetal malformation, it may take longer to reach a diagnosis and at the same time it could present contraindications for the MA. This would be one explanation to the difference between the two groups in both variables. Nevertheless, these differences could also be due to other factors, like the kind of intervention that is being offered to the women that could influence their election and profile. As it was shown in a study that compared MA versus surgical [20], women choosing MA would only prefer other MA in two thirds of cases, if she had to face a new abortion. But woman who had surgical abortion would choose another surgical in almost all the cases, showing a best preference for the last option.

On the basis of the results presented above, we strongly recommend implementing MA in primary care centres (SRHU) as far as it implies a better accessibility to the treatments without increasing the number and rate of abortions. The procedure shows to be safe and with a range of failure within the standards. Furthermore, as the characteristics of women that have experienced the two main types of procedures are quite different, it reinforces the principle that physicians recommending MA treatment should offer women detailed and unbiased information of all options. Women should know adequately all the risks and benefits of all the techniques, and they should have the right to choose the method for the abortion.

The main limitation of the study is that MA failures cannot be assessed for all the cases included in the analysis, because the official statistics are not yet collecting this information. However, we obtained data from a sample of centers since the year 2013. Considering a failure as "the terminations with an incomplete abortion requiring intervention with other methods (aspiration, surgery, etc.) or continuing with the pregnancy", we have estimated that failure rate was $2.0 \%$ for 2013 and $2.1 \%$ for 2014 . According to the literature, failures can occur 
in a range between $1.0 \%$ and $10.0 \%$ of MA [2] [18], thus we consider that the figures obtained by the program, are good results.

Another limitation to assess the results is the range of protocols being used besides the one recommended by the Ministry of Health. As far the protocol is not compulsory, but a recommendation, some centers (mainly hospitals and outpatients centers) have adapted the protocol according to the specific profile of the women attending the site, the medical indications and their preferences or expectations. That aspect could reduce somewhat the comparability of the results among the centers but, on the other hand, it implies a relevant aspect on the acceptability of the program, because takes into account the preferences of women.

Compared to other countries, MA in Catalonia is having a shorter but faster career. In United States, where MA was approved in September 2000 [21] it increased more than 6 times in a 10 years period [22] [23], and in France [24] [25], a similar rise took place in twenty years. However, in Catalonia, MA has had the same expansion, but only in a 4 years period, what would suggest the acceptability and efficiency of the program. However, its frequency of use has not yet reached the levels of these countries, where they have longer career with MA. It is expected an upward trend of MA in Catalonia, for some years. Although, physicians recommending this treatment have to remind that women should always have the right to choose the method for their TOP [26].

\section{Conclusions}

MA program implementation has allowed easier access to abortion services. This public health program has been one of the reasons for the substantial increase of MA during this period.

The availability of MA has led to an increase in the proportion of the abortions performed at earlier stages and has reduced the number of surgical procedures, allowing to positive outcomes both, in terms of health and economy.

This improvement has not produced an increase in the number nor rate of abortions but has provided women with the opportunity to choose the method better adapted to their preferences. Moreover, MA has caused a change in the pattern of treatment, especially in hospitals.

Finally, MA implementation in Catalonia has had a rise, sharper and faster than in other countries. But even if it is probable an upward trend of MA for some years, physicians recommending this treatment have to remind that women, after they have been informed adequately of the risks and benefits of all the techniques, should have the right to choose the method for abortion.

\section{Competing Interests}

The authors declare that they have no competing interests.

\section{Authors' Contributions}

Rosa Gispert, Carme Ollé and Roser Bosser initiated the study and overall de- 
sign. Neus Prat, Pilar Magrinyà and Carme Coll were involved in the first draft. Ramón Escuriet, Rosa Gispert, Roser Bosser and Carme Ollé were involved in the discussion and interpretation of results. Ricard Tresserras and Joaquim Calaf made a revision of the first draft. Rosa Gispert, Roser Bosser and Carme Ollé wrote de final draft.

All authors read and approved the final manuscript.

\section{Acknowledgements}

To the members of the working group which developed the medical abortion protocol in Catalonia: Amèlia Acera, Rosa Almirall, Àngels Avecilla, Margarita Aznar, Roser Bosser, Elena Català, Carme Coll, Carles Constante, Dolors Costa, Maria Luisa de la Puente, David Elvira, Ramon Escuriet, Gemma Falguera, Josep Fusté, Josep Grau, Cristina Martínez, Hildegard Mausbach, Dolors Muñoz, Neus Prat, Elisenda Prats, Nereida Prats, Manel Rabanal, Neus Rams, Marta Roig, Josefina Rovira, Pilar Soteras, Berta Sunyer, Núria Torres and Eva Vela.

To the people working in the Abortion Register of Catalonia: Mar Torné, Marta Saló, and Roser Martí.

To all centres attending women, which are responsible for abortion's data submission.

\section{References}

[1] (2015) Medical Abortion. In Wikipedia, The Free Encyclopedia. http://en.wikipedia.org/w/index.php?title=Medical_abortion\&oldid=631780679

[2] Trupin, S.R. and Moreno, C. (2001) Medical Abortion: Overview and Management. Medscape Women's Health, 6, 4. https://www.ncbi.nlm.nih.gov/pubmed/11965218

[3] Lohr, P.A., Wade, J., Riley, L., Fitzgibbon, A. and Furedi, A. (2010) Women's Opinions on the Home Management of Early Medical Abortion in the UK. Journal of Family Planning and Reproductive Health Care, 36, 21-25.

http://jfprhc.bmj.com/content/36/1/21.long https://doi.org/10.1783/147118910790290894

[4] (2014) Protocol de la interrupció voluntària de l'embaràs (IVE) farmacològica fins als 63 dies d'embaràs. Departament de Salut, Generalitat de Catalunya. http://canalsalut.gencat.cat/web/.content/contingut_responsiu/salutAZ/I/interrupci o_voluntaria_embaras/documents_prof/arxius/protocol_def_63.pdf

[5] Medical versus Surgical Abortion. University of California, San Francisco. USCF Medical Center. https://www.ucsfhealth.org/education/medical_versus_surgical_abortion/

[6] Jones, R.K. and Henshaw, S.K. (2002) Mifespristone for Early Medical Abortion: Experiences in France, Great Britain and Sweden. Perspectives on Sexual and Reproductive Health. Guttmatcher Institute, 34, 154-161. http://www.guttmacher.org/pubs/journals/3415402.pdf

[7] (2013) Word Abortion Policies. Department of Economic and Social Affairs, Population Division, United Nations.

http://www.un.org/en/development/desa/population/publications/pdf/policy/Worl dAbortionPolicies2013/WorldAbortionPolicies2013_WallChart.pdf

[8] (1985) Organic Law 9/1985. July 5, Reform of Article 417 Bis of the Penal Code. BOE, No. 166, 22041. 
https://www.boe.es/boe/dias/1985/07/12/pdfs/A22041-22041.pdf

[9] Organic Law 2/2010 of 3 March, Sexual and Reproductive Health and Voluntary Interruption of Pregnancy.

http://www.boe.es/boe/dias/2010/03/04/pdfs/BOE-A-2010-3514.pdf

[10] WHO. Abortion without Risks. Policy and Technical Guide for Health Systems. Second Edition, Geneva. http://apps.who.int/iris/bitstream/10665/77079/1/9789243548432_spa.pdf?ua=1

[11] Ollé, C., Bosser, R., Prat, N., Coll, C., Magrinyà, P. and Gispert, R. (2014) Process of the Development of Medical Abortion in Catalonia.

http://salutweb.gencat.cat/web/.content/home/el_departament/estadistiques_sanitar ies/dades_de_salut_i_serveis_sanitaris/interrupcio_voluntaria_de_lembaras_ive/d ocuments/avortament_farmacologic_angles.pdf

[12] Sunyer, B. and Sola-Morales, O. (2011) Interrupció farmacològica voluntària de l'embaràs. Agència d'Informació,Avaluació i Qualitat en Salut. Servei Català de la Salut. Departament de Salut. Generalitat de Catalunya, Barcelona.

http://aquas.gencat.cat/web/.content/minisite/aquas/publicacions/2011/pdf/ive_far macologica_aiaqs2011ca.pdf

[13] (2014) Protocol de la interrupció voluntària de l'embaràs (IVE) farmacològica fins als 63 dies d'embaràs. Departament de Salut, Generalitat de Catalunya.

http://canalsalut.gencat.cat/web/.content/contingut_responsiu/salutAZ/I/interrupci o_voluntaria_embaras/documents_prof/arxius/protocol_def_63.pdf

[14] (2011) Avaluació de la primera fase d'implantació de les recomanacions del Protocol de la interrupció voluntària de l'embaràs (IVE) farmacològica. Departament de Salut, Generalitat de Catalunya.

http://scientiasalut.gencat.cat/bitstream/handle/11351/1900/avaluacio_protocol_ive 2011.pdf?sequence $=1$

[15] Generalitat de Catalunya. Departament de Salut. Interrupció voluntària de l'embaràs. http://salutweb.gencat.cat/ca/el_departament/estadistiques_sanitaries/dades_de_sal ut_i_serveis_sanitaris/interrupcio_voluntaria_de_lembaras_ive/

[16] Ministerio de Sanidad, Servicios Sociales e Igualdad. Interrupciones voluntarias del embarazo.

http://www.msssi.gob.es/profesionales/saludPublica/prevPromocion/embarazo/ho me.htm\#publicacion

[17] Harvey, S.M., Beckman, L.J., Castle, M.A. and Coeytaux, F. (1995) Knowledge and Perceptions of Medical Abortion among Potential Users. Family Planning Perspectives, 27, 203-207. http://www.guttmacher.org/pubs/journals/2720395.pdf https://doi.org/10.2307/2136276

[18] Raymond, E.G., Shannon, C., Weaver, M.A. and Winikoff, B. (2013) First-Trimester Medical Abortion with Mifespristone $200 \mathrm{mg}$ and Misoprostol: A Systematic Review. Contraception, 87, 26-37. https://doi.org/10.1016/j.contraception.2012.06.011

[19] Goodyear-Smith, F. and Knowless, A. (2009) Choosing Medical or Surgical Terminations of Pregnancy in the First Trimester: What Is the Difference? Australian and New Zealand Journal of Obstetrics and Gynaecology, 49, 211-215.

http://www.ncbi.nlm.nih.gov/pubmed/19432614

https://doi.org/10.1111/j.1479-828X.2009.00967.x

[20] Creinin, M.D. (2002) Randomized Comparison of Efficacy, Acceptability and Cost of Medical versus Surgical Abortion. Contraception, 62, 117-124.

http://www.ncbi.nlm.nih.gov/pubmed/11124358 https://doi.org/10.1016/S0010-7824(00)00151-7

[21] Centers for Disease Control and Prevention (2011) Abortion Surveillance, United 
States, 2010. Morbidity and Mortality Weekly Report, 62, 1-44.

http://www.cdc.gov/mmwr/pdf/ss/ss6208.pdf

[22] Pazol, K., Creanga, A.A. and Zane, S.B. (2012) Trends in Use of Medical Abortion in the United States: Reanalysis of Surveillance Data from the Centers for Disease Control and Prevention. Contraception, 86, 746-751.

http://www.ncbi.nlm.nih.gov/pubmed/22770796 https://doi.org/10.1016/j.contraception.2012.05.023

[23] Jones, R.K. and Jerman, J. (2011) Abortion Incidence and Service Availability in the United States, 2011. Perspectives on Sexual and Reproductive Health, 46, 3-14.

https://www.guttmacher.org/pubs/journals/psrh.46e0414.pdf https://doi.org/10.1363/46e0414

[24] Lamarche-Vadel, A., Moureau, C., Warszawski, J., Bajos, N. and Equipe, C. (2005) Side Effects of Induced Abortion: Results from a Population-Based Survey. Gynécologie Obstétrique \& Fertilité, 33, 113-118.

http://www.ncbi.nlm.nih.gov/pubmed/15848082 https://doi.org/10.1016/j.gyobfe.2005.02.016

[25] Vilain, A. and Moquet, M.C. (2004) Les interruptions volontaires de grossesse en 2002. Direction de la recherche, des études, de l'évaluation et des statistiques (DREES), Ministère des Affaires sociales, de la Santé et des Droits des femmes. http://drees.social-sante.gouv.fr/IMG/pdf/er843.pdf

[26] Lim, L.M. and Singh, K. (2014) Methods of Abortion in First and Second Trimester. Open Journal of Obstetrics and Gynecology, 4, 924-929. http://file.scirp.org/pdf/OJOG_2014110513495632.pdf https://doi.org/10.4236/ojog.2014.415130

Submit or recommend next manuscript to SCIRP and we will provide best service for you:

Accepting pre-submission inquiries through Email, Facebook, LinkedIn, Twitter, etc. A wide selection of journals (inclusive of 9 subjects, more than 200 journals)

Providing 24-hour high-quality service

User-friendly online submission system

Fair and swift peer-review system

Efficient typesetting and proofreading procedure

Display of the result of downloads and visits, as well as the number of cited articles Maximum dissemination of your research work

Submit your manuscript at: http://papersubmission.scirp.org/

Or contact ojog@scirp.org 